\title{
Immigrants' Health in Europe: A Cross-Classified Multilevel Approach to Examine Origin Country, Destination Country, and Community Effects
}

Tim Huijts

Gerbert Kraaykamp

Radboud University

In this study, we examined origin, destination, and community effects on first- and second-generation immigrants' health in Europe. We used information from the European Social Surveys (2002-2008) on 19,210 immigrants from 123 countries of origin, living in 31 European countries. Cross-classified multilevel regression analyses reveal that political suppression in the origin country and living in countries with large numbers of immigrant peers have a detrimental influence on immigrants' health. Originating from predominantly Islamic countries and good average health among natives in the destination country appear to be beneficial. Additionally, the results point toward health selection mechanisms into migration.

\section{INTRODUCTION}

During the last few decades, Europe has experienced a substantial influx of immigrants from all parts of the globe (Castles and Miller, 2003). Additionally, within Europe, there have been considerable migration flows between countries. Recently, the ongoing process of European political and economic integration has further facilitated movement of citizens between all member states of the European Union. The growing share of immigrants in European societies has spurred researchers from several disciplines to examine the living conditions and social and economic performance of immigrants and their offspring ( $c f$. Van Tubergen, 2006). The available evidence has indicated that some immigrant groups appear to outperform other immigrant groups in areas such as the labor market and the educational system. 
In medical sociology and social epidemiology, the increasing numbers of immigrants in European societies have attracted considerable attention as well. For the field of health policy research, differences between immigrant groups in the health problems they experience have implications for future changes in the demand for specific forms of health care (Evans, 1987). Additionally, migration is often regarded as a "natural experiment" by epidemiologists, given that immigrants' social context is changed radically after migration. Comparing the health of several immigrant groups may, therefore, shed light on the relative contribution of people's living conditions in early life and their current social environment to health and well-being in the general population ( $c f$. Kasl and Berkman, 1983; Vega and Rumbaut, 1991; Carballo, Divino, and Zeric, 1998).

As a result, numerous studies have examined immigrants' health, well-being, and mortality in European countries. This large body of earlier work has laid bare considerable differences within the immigrant population. First, several studies have focused on comparing different immigrant groups within single European countries. In Sweden, immigrants from Southern Europe reported substantially poorer health and had higher risks of cardiovascular disease than immigrants from other regions (Pudaric, Sundquist, and Johansson, 2003). Existing research on the Netherlands points at lower mortality and a lower risk of cardiovascular disease among Moroccans as compared to Surinamese and Antillean immigrants (Bos et al., 2004; Stirbu et al., 2006a,b). In the United Kingdom, Bangladeshi, Black Caribbeans, Pakistani, and Indians have an elevated risk of poor health in comparison with immigrants with a Chinese or Irish background (Smith, Kelly, and Nazroo, 2009). Together, these findings have led to the suggestion that experiences prior to migration in immigrants' country of origin may contribute to the risk of poor health and illness. Socialization of health behavior, deprivation, and illness during childhood, and traumatic experiences in wars and political conflicts have most frequently been offered as possible causes of these variations between immigrant groups.

A second yet smaller strand of research has compared health of immigrants from single origin countries across multiple host contexts. A study comparing immigrants' health across regions within Belgium demonstrated that immigrants report poorer health in regions with high unemployment and a lack of public services (Lorant, Van Oyen, and Thomas, 2008). Finnish men living in Sweden are in better health than 
Finns living in Finland (Westman et al., 2008). As a classic example outside Europe, a series of studies comparing Japanese men living in Japan, Hawaii, and California ( $c f$. Kasl and Berkman, 1983) revealed that Japanese men in California had higher blood pressure levels, higher cholesterol, and a higher risk of coronary heart disease than Japanese men in Japan and Hawaii. On the whole, the available evidence from this line of research implies that immigrants' current living environment (i.e., the country of destination) is influential to their health and well-being. The most prominent explanations for these variations across countries of destination include discrimination of immigrants, the quality and quantity of social networks, the quality and accessibility of the health care system, and health behavior and lifestyle factors among the native population.

In sum, the literature on immigrants' health abundantly offers theoretical implications and suggestions on how immigrants' country of origin and their country of destination may account for variations in immigrants' health. However, up until now, research containing actual tests of origin effects and destination effects has been lacking. As several scholars in this field have acknowledged, adequately assessing to what extent characteristics of the country of origin influence immigrants' health is problematic if immigrants from single destination countries are examined (Kasl and Berkman, 1983; Berry et al., 1987). In a similar way, it is difficult to judge the impact of destination country characteristics if only immigrants from a single origin country are included (Gee, 2002). Consequently, to properly test hypotheses on origin and destination effects on immigrants' health, this calls for an approach in which immigrants from multiple origin countries and multiple countries of destination are examined simultaneously. This so-called double comparative design has been fruitfully used to disentangle origin and destination effects on immigrants' language proficiency, religious involvement, labor market participation, and educational performance (Van Tubergen, 2006; Levels, Dronkers, and Kraaykamp, 2008).

Apart from disentangling origin and destination effects, the double comparative design allows for separating the influence of characteristics of specific combinations of origin groups and destination countries. These so-called community effects (Van Tubergen, 2006; Levels, Dronkers, and Kraaykamp, 2008) refer to the influence of specific immigrant communities on health that can not be attributed to characteristics of the origin and destination countries. For example, the fact that Turkish immigrants in Germany have a lower mortality risk than the native German 
population (Razum et al., 1998) can not be solely attributed to characteristics of German society; moreover, these immigrants also appeared to have lower mortality rates than a control group of Turks living in Turkey. Therefore, characteristics that are specific to the Turkish community in Germany (e.g., relative group size or selective immigration) are responsible for this finding. By distinguishing community effects in addition to origin country and destination country effects, it can be tested whether belonging to specific communities is influential to immigrants' health next to their origin and destination countries.

To our knowledge, the double comparative design has never been applied in research examining immigrants' health. In this study, we were able to use information on 19,210 immigrants from 123 countries of origin living in 31 European countries of destination to simultaneously test the influence of origin country and destination country characteristics on immigrants' health. Whereas earlier research has mostly focused on Western European destination countries, our study also examined immigrants' health in 11 countries in Eastern Europe. Given that three of the world's ten largest immigrant receiving societies are located in Eastern Europe (i.e., the Russian Federation, Ukraine, and Poland; World Bank, 2007), the inclusion of these countries further adds to the generalizability of our findings. Information on several individual characteristics was used to further clarify the mechanisms through which properties of origin and destination countries influence health. A validated and cross-culturally comparable self-rated health measurement is used to indicate immigrants' general physical and mental health status (Chandola and Jenkinson, 2000).

We conducted separate analyses for first- and second-generation immigrants (i.e., the native-born offspring of foreign-born immigrants). Because first- and second-generation immigrants were socialized in highly different social contexts, a separate test of effects may elucidate the relative importance of conditions in early life and people's current living environment for the risk of poor health and illness. Whereas several authors have found that health inequalities between immigrant groups are smaller or even absent for the second generation (Saraiva Leao et al., 2005, 2009; Ho, Bos, and Kunst, 2007), others have found that health differences persist among the offspring of foreign-born people (Kuo, 1976; Reijneveld, 1998; Smith, Kelly, and Nazroo, 2009).

In sum, the following research question is addressed in this study: To what extent do (1) characteristics of the country of origin; (2) 
characteristics of the country of destination; and (3) characteristics of specific immigrant communities influence first- and second-generation immigrants' self-rated health in Europe?

\section{THEORY AND HYPOTHESES}

\section{Hypotheses on Origin Effects}

Three effects of characteristics of the country of origin on immigrants' health are expected, all of which stem from theoretical perspectives on living conditions prior to migration. First, immigrants' health is expected to be associated with the health of natives in the origin country. Ho, Bos, and Kunst (2007) have suggested that their finding of higher mortality rates among Indonesians in the Netherlands may be caused by infections during childhood having a lasting impact on immigrants' health. Additionally, malnutrition, illness, and adversity in early life partly determine health in adulthood (Gagnon and Mazan, 2009). Finally, the health of natives in the origin country may reflect genetic factors that are specific to origin countries, and the capability of the health system of the origin country to prevent and cure ill health prior to migration. Furthermore, because of these genetic factors, health inequalities based on immigrants' country of origin may be passed on to the second generation. Therefore, we expect that immigrants report poorer health as natives in their country of origin are in poorer health (Hypothesis 1).

Second, socialization of health behavior during childhood may be a determinant of immigrants' health. After all, because it is hard to shake off long-learned habits, patterns of health-related behavior often persist after migration. Most prominently, healthy lifestyles may be shaped by religious socialization and sanctioning of unhealthy behavior. Religious denominations often have strong guidelines on habits, such as overindulgence and the consumption of alcohol, and sanction behavior that conflicts with these guidelines both internally and externally. This means that not only religious individuals, but also people living in a highly religious environment are more prone to refrain from health-damaging behavior. Of all major religions, Islam most clearly and strongly sanctions unhealthy behavior, especially the consumption of alcohol. Previous research has indicated that this translates into the lowest risk of hospitalization for alcohol-related disorders among immigrants from the Middle East (Hjern and Allebeck, 2004), and the lowest smoking prevalence among women 
born in Arabic-speaking countries (Lindstrom and Sundquist, 2002). Additionally, this may explain why Moroccans and Turks have relatively low mortality rates as compared to other immigrant groups in the Netherlands (Bos et al., 2004; Stirbu et al., 2006b). Furthermore, immigrants from Islamic countries of origin may pass these healthy lifestyles on to their offspring. We, therefore, hypothesize that immigrants from predominantly Islamic countries of origin report better health than immigrants from countries of origin with other predominant religious denominations (Hypothesis 2).

Third, the level of political suppression in the origin country may affect immigrants' health. Knipscheer and Kleber (2006) found that posttraumatic reactions among Bosnian refugees were highly predictive of mental health problems. Additionally, the level of political suppression in the country of origin is negatively related to immigrants' economic performance (Van Tubergen, 2006), which may translate into stronger material deprivation among refugees. These adverse effects of political suppression appear to be transferred to second-generation immigrants as well: children of Norwegian-born Jewish holocaust survivors show high psychological vulnerability (Major, 1996). In sum, we expect that immigrants report poorer health as they originate from countries with higher degrees of political suppression (Hypothesis 3).

\section{Hypotheses on Destination Effects}

Four expectations on effects of destination country characteristics on immigrants' health are derived. First, based on acculturation theory (Berry et al., 1987), the health of natives in the destination country is expected to be a strong determinant of immigrants' health. By adapting to the lifestyle patterns of the native population in the country of destination, immigrants' risk of smoking, obesity, hypertension, and chronic conditions rapidly converges to the level of the native group (Singh and Siahpush, 2002). Similarly, Harding (2004) has demonstrated that mortality rates of Caribbean immigrants in England and Wales converge to the level of the destination country. Additionally, the health of the native population may reflect other circumstances in the country of destination (e.g., the quality of the health care system, infectious diseases, and pollution) that influence both natives and immigrants equally. We, therefore, expect to find that immigrants report better health as the average reported health status of natives in their country of destination is higher (Hypothesis 4). 
Second, we expect discrimination of immigrants in the destination country to affect immigrants' health. Perceived discrimination by immigrants is associated with stronger mental health problems, an increased risk of psychosis and schizophrenia, higher blood pressure, and lower life satisfaction (Krieger and Sidney, 1996; Finch, Kolody, and Vega, 2000; Gee, 2002; Williams, Neighbors, and Jackson, 2003; Veling et al., 2007; Safi, 2010). Immigrants encounter discrimination, prejudice, and hostility from natives in daily life, during social interaction, and in the educational system and the labor market. In addition, the perception of racism in wider society has an independent effect on the risk of common mental disorder and psychosis among minority groups (Karlsen et al., 2005). Smith, Kelly, and Nazroo (2009) have pointed out that the detrimental effects of discrimination may still be present in the second generation, because second-generation immigrants experience new areas, levels, and forms of discrimination as compared to first-generation immigrants. In sum, we expect that immigrants report poorer health as natives' attitudes toward immigrants in their country of destination are more disapproving (Hypothesis 5).

Finally, two contrasting expectations are derived on the influence of the level of social engagement among natives in the country of destination. From an acculturation perspective, we would expect that living in countries with high levels of social interaction and strong social networks among natives may be beneficial to immigrants' health. After all, in societies with high social engagement, it may be easier for immigrants to form new social relationships and to find sources of social interaction and social support. This is in line with evidence on the beneficial effect that living in societies with high levels of social engagement may have on people's health, over and above the salutary role of personal social networks (Kawachi, Kennedy, and Glass, 1999). Consequently, we hypothesize that immigrants report better health as the level of social engagement among natives in the country of destination is higher (Hypothesis 6a).

Conversely, using insights from theories on ethnic social capital leads to an opposing expectation. After all, if social engagement is segmented along ethnic lines, high social engagement among natives may not necessarily have positive externalities to immigrants' health ( $c f$. Portes, 1998) and may even lead to stronger feelings of social isolation among immigrants and their offspring (Kuo, 1976). In addition, obtaining access to the labor market may be more difficult for immigrants if informal ties among natives are stronger. Anson (2002) has found that mortality 
among immigrants is higher in Belgian communities with stronger family ties and networks among natives. As a result, in contrast to predictions based on acculturation theory, using the assumption that social networks may be segmented across ethnic lines leads to the expectation that immigrants report poorer health as the level of social engagement among natives in the country of destination is higher (Hypothesis 6b).

\section{Hypotheses on Community Effects}

Four hypotheses on the effect of community characteristics on immigrants' health are tested in this study. First, we expect immigrants to experience fewer acculturation problems if the cultural distance between their country of origin and the country of destination is smaller. We assume that this is especially the case if the country of origin and the country of destination have had a colonial relationship in the past, or if the country of origin and the country of destination used to be part of the same country in recent history. After all, in these cases, immigrants have already been acquainted with the language and culture of the destination country in the period prior to migration. In turn, destination language proficiency and cultural differences between the origin country and the destination country appeared to account for a large part of differences in immigrants' self-reported health (Wiking, Johansson, and Sundquist, 2004). Based on acculturation theory, we, therefore, expect that immigrants living in countries of destination that have colonial or shared historical ties with their country of origin report better health than immigrants living in countries without historical ties with their country of origin (Hypothesis 7).

Second, two contrasting expectations can be formulated on the influence of the relative size of an immigrant's community in the country of destination on their health. Building on theoretical perspectives on ethnic social capital, living among relatively large numbers of peers from the same country of origin may be beneficial to immigrants' health ( $c f$. Pickett and Wilkinson, 2008). Previous work on several destination countries suggests that immigrants have less psychological symptomatology and a smaller risk of poor health and psychotic disorders as their own community is larger (Gee, 2002; Veling et al., 2008; Becares, Nazroo, and Stafford, 2009). Additionally, mortality risks among immigrants appear to be lower in communities with large proportions of immigrant peers (LeClere, Rogers, and Peters, 1997; Anson, 2002). Finally, the fact that a higher relative immigrant group size is associated with better educational performance 
and increased labor force activity (Van Tubergen, 2006; Levels, Dronkers, and Kraaykamp, 2008) may translate into less frustration and material deprivation among immigrants from larger communities. Together, this leads to the expectation that immigrants report better health as the relative size of their immigrant community in their country of destination is larger (Hypothesis 8a).

On the other hand, according to acculturation theory, the presence of large numbers of peers from the same country of origin may in fact hamper integration into the destination society (cf. Portes, 1998). Large communities may increase the risk of living in deprived areas with low-quality housing (Becares, Nazroo, and Stafford, 2009). Lorant, Van Oyen, and Thomas (2008) have found that high migrant concentration in regions is associated with poor health among immigrants. Furthermore, Van Tubergen (2006) found that a higher relative community size decreases destination language proficiency and immigrants' occupational status, which may in turn lead to a higher risk of reporting poor health (Wiking, Johansson, and Sundquist, 2004). We, therefore, expect that immigrants report poorer health as the relative size of their immigrant community in their country of destination is larger (Hypothesis 8b).

Finally, we expect the geographical distance between immigrants' origin country and their country of destination to be associated with health. The healthy migrant hypothesis (Abraido-Lanza et al., 1999) suggests that people who decide to emigrate are relatively healthy: after all, for healthy people, the costs of emigration are lower (i.e., they can do without the support and care of relatives that unhealthy people often require), and the benefits are higher (the chances of improved living conditions strongly depend on the capacity to earn a living). As travel costs are higher as the distance between the country of origin and the country of destination is larger, we expect that immigrants are a more selective group of relatively healthy people in immigrant communities where the geographical distance between both countries is larger. In sum, our final hypothesis reads that immigrants report better health as the geographical distance between their country of origin and their country of destination is larger (Hypothesis 9). Because the migration experience does not apply to second-generation immigrants, we only expect to find an effect of the geographical distance between the origin country and the destination country for first-generation immigrants. 


\section{Individual Characteristics}

No explicit hypotheses on effects of individual characteristics on immigrants' health are formulated and tested in this study. However, we did include a number of individual characteristics in the analyses, to shed more light on the mechanisms underlying the origin, destination, and community effects that we hypothesized. Information on immigrants' educational level and employment status was included to examine whether origin, destination, and community effects on immigrants' health can be attributed to material deprivation and success in the labor market and the educational system. The level of urbanization was accounted for to examine whether effects are explained by an "urban health penalty" for migrants (Lorant, Van Oyen, and Thomas, 2008). We controlled for immigrants' individual religious affiliation, to adequately separate the effect from originating from an Islamic country from the influence of individual religious involvement. To assess whether effects are because of differences between immigrant groups in the availability of individual social ties, we accounted for immigrants' individual social engagement, marital status and the presence of children in the household. By including immigrants' length of stay in the destination country, we are able to examine whether the healthy migrant effect in Hypothesis 9 is explained by the fact that the health advantage of migrants wears off in the course of time because of acculturation. We included perceived discrimination by immigrants to examine whether this mediates the effect of anti-immigrant attitudes on health. Finally, gender and age were controlled for to account for differences in the demographic composition of immigrant groups.

\section{DATA AND MEASUREMENTS}

\section{Data, Classification of Immigrants, and Sample Construction}

To test our hypotheses, we pooled data from the European Social Surveys (ESS) conducted in 2002, 2004, 2006, and 2008 (Jowell and The Central Co-ordinating Team, 2003; Jowell and The Central Co-ordinating Team, 2005; Jowell and The Central Co-ordinating Team, 2007; Jowell and The Central Co-ordinating Team, 2009). These data are archived and distributed by the Norwegian Social Science Data Services (NSD). The ESS are representative surveys containing information on 170,400 individuals aged 15 and over living in private households from 30 European 
countries, Israel, and Turkey. On the whole, the ESS samples are of a high quality and cross-national comparability, the measurements are both reliable and valid, and the mean response rate exceeds $60 \% .^{1}$

Although the ESS were not specifically aimed at immigrants, a substantial part of the respondents could be identified as first- or secondgeneration immigrants. (For a detailed description of the procedure we used to distinguish first- and second-generation immigrants in the ESS, we refer to Appendix). Because respondents were interviewed in the official language of the country of destination, poorly acculturated immigrants may be underrepresented in these data. However, comparing results of general population surveys and specific migrant surveys, in which bilingual interviewers were used, Van Tubergen (2006) did not find an influence of the survey type on the effects of the origin, destination, and community characteristics on his outcome variables. Therefore, it is reasonable to assume that the lack of bilingual interviewers in the ESS will not have influenced our results.

After assigning countries of origin to first- and second-generation immigrants, we combined information on the country of residence and the country of origin to create immigrant communities. Following Levels, Dronkers, and Kraaykamp (2008), we decided to exclude communities with fewer than five respondents. As Clarke (2008) has demonstrated, in multilevel models, a minimum of five observations nested within each higher level unit is needed to obtain reliable and stable estimates. Including communities with fewer than five respondents would, therefore, be problematic for an accurate estimation of community effects. Additionally, not all countries of destination have inhabitants from all origin groups. Thus, although a total number of $32 * 197=6,304$ communities would have been possible, we were left with 465 different immigrant communities for first-generation immigrants, and 235 communities for second-generation immigrants (communities were computed separately to allow for

\footnotetext{
${ }^{1}$ The 30 European countries covered in the ESS are Austria, Belgium, Bulgaria, Cyprus, Czech Republic, Denmark, Estonia, Finland, France, Germany, Greece, Hungary, Iceland, Ireland, Italy, Latvia, Luxembourg, the Netherlands, Norway, Poland, Portugal, Romania, Russian Federation, Slovenia, Slovakia, Spain, Sweden, Switzerland, Ukraine, and United Kingdom. Although Israel and Turkey are not part of Europe and different from European societies in several respects, we did not exclude these countries, because this would result in an unnecessary loss of respondents. Most countries did not participate in all four ESS waves. For more country-specific information, such as which ESS waves were conducted and detailed figures on response rates per survey wave, we refer to the documentation on the ESS website (http://www.europeansocialsurvey.org).
} 
separate analyses of both groups). This results in a loss of 2,498 firstgeneration immigrants (17.2\%), and 1,649 second-generation immigrants (18.6\%). In addition, excluding communities with fewer than five respondents resulted in the loss of Romania (for both generations) and Iceland (for second-generation immigrants only) as destination countries.

To prevent the loss of additional communities with five to ten respondents, we avoided the exclusion of respondents with missing values on the variables in our models. Instead, we either created additional dummy variables to indicate respondents with missing information (in case of categorical measures), or assigned the mean values to respondents for whom information was lacking (for continuous variables). The only exceptions were made for respondents with missing information on gender or the dependent variable $(n=44)$; they were removed from the sample. In total, this leaves us with 12,033 first-generation immigrants from 122 countries of origin living in 31 countries of destination, and 7,177 second-generation immigrants from 75 countries of origin located in 28 countries of destination. An overview of the countries of origin and the communities included in this study is available upon request from the authors.

\section{Dependent Variable: Self-Rated Health}

In the ESS, self-rated health was measured by asking respondents how their health is in general. Five answering categories were available: "very bad" (coded 0), "bad" (1), "fair" (2), "good" (3), and "very good" (4). It has been repeatedly demonstrated that this measure is a strong and valid predictor of subsequent morbidity and mortality (Idler \& Benyamini, 1997). Moreover, self-rated health appears to be equally valid and predictive across ethnic groups (McGee et al., 1999; Chandola and Jenkinson, 2000). Because the original variable is not normally distributed, we used a dichotomized version (i.e., coding categories 3 and 4 as "good or very good health" (0) and categories 0 to 2 as "poor health" (1)) of this indicator as our dependent variable. Using the original measure in linear models did not lead to different results, which indicates that our findings are robust to different operationalizations of the dependent variable.

\section{Origin Variables}

We included three characteristics of immigrants' country of origin. We decided to measure all characteristics of the country of origin in the 
period between 1990 and 2000. Given that the first ESS wave was conducted in 2002, this at least means that all origin characteristics represent the situation prior to the data collection. The choice of this specific time span was also driven by practical reasons: after 1990, several new countries were formed (especially in Eastern Europe) for which information would not be available prior to 1990 .

To measure the health of natives in the origin country, we included the adult mortality rate (i.e., the death rate between 15 and 60 years per 1000 inhabitants) of the country of origin (WHO, 2009). We only used mortality rates in 1990, because mortality rates for the rest of the decade were not available. Although this measure may seem crude, it is the only reliable and consistently available indicator of health when examining large numbers of non-Western countries. Additionally, since self-rated health is a strong predictor of mortality (Idler and Benyamini, 1997), this indicator may adequately reflect health of natives in the origin country. For the analyses, we divided the adult mortality rate by 100 to facilitate the interpretation of the parameters.

To assess whether the country of origin was predominantly Islamic, information from the CIA World Factbook (2009) was used. Countries were regarded as being predominantly Islamic if the (estimated) percentage of Muslims was larger than $50 \%$. If countries were predominantly Islamic between 1990 and 2000 (i.e., in the majority of the years), they were coded (1) on this variable, countries with other or no predominant religions were coded (0).

Political suppression was measured using information from Freedom House (2009). In the yearly Freedom in the World Survey, countries are judged on two scales (i.e., political rights and civil liberties). Scores on both scales range from 1 (indicating the highest degree of freedom) to 7 (the lowest degree of freedom). We first summed each country's scores on both scales for each year between 1990 and 2000, and then computed the average score for the whole decade. This resulted in a new scale, ranging from 2 to 14, with a higher score reflecting stronger political suppression.

\section{Destination Variables}

Four characteristics of the country of destination were included in our models. To measure the mean health status of the native population, we computed the mean self-rated health score for the native respondents in the ESS for each destination country, using the original non-dichotomized measure. 
To determine the extent of anti-immigrant attitudes for each destination country, we used information on the native respondents in the ESS $(n=142,395)$. Three items measuring attitudes toward immigrants were available in all four waves of the ESS. Respondents were asked to what extent it is generally bad or good for their country's economy, to what extent their country's cultural life is generally undermined or enriched, and whether their country would be a worse or a better place to live by people coming to live there from other countries. Eleven answering categories were available for each item; we recoded the items so that high scores reflected the most disapproving attitudes toward immigrants. Together, these three items appeared to form a reliable scale in all countries (mean Cronbach's $\alpha=0.84$ ). We computed the unweighed mean score on these three items for each native respondent and used each country's mean score on this newly formed scale in the analyses.

Information on the native respondents in the ESS was used as well to determine the degree of social engagement among natives. Respondents were asked how often they socially meet with friends, relatives, and colleagues. The answering categories ranged from "never" (coded 0) to "everyday" (6). For each destination country, we computed the mean score among native respondents on this item for inclusion in our models. Measures of formal social participation (e.g., involvement in voluntary associations) were not consistently available in the ESS.

Finally, to account for differences between the four ESS survey waves, we included a continuous variable measuring the survey year, ranging from 2002 (coded 0) to 2008 (3) for first-generation immigrants and between 2004 (0) and 2008 (2) for second-generation immigrants.

\section{Community Variables}

Three characteristics of specific immigrant communities were used. To indicate the presence of colonial or shared historical ties between the country of origin and the country of destination, immigrant communities were coded (1) in case of a colonial or shared past between the origin and destination country. If there was no colonial or shared history, communities were coded (0). It should be noted that a colonial or shared past does not only refer to, for instance, the relationship between former French colonies and France. For example, the Russian community in Latvia is also regarded as a community with historical ties between the country of origin and the country of destination, because of the shared past of both 
countries. The same applies to the other former Soviet republics, the countries in former Yugoslavia, and former Czechoslovakia.

The relative group size of each immigrant community was computed as a percentage of the total population of the destination country. Information on the absolute group size of all immigrant communities was obtained from the Global Migrant Origin Database (Parsons et al., 2007), which is based on censuses taken between 1995 and 2004. It should be noted that only first-generation immigrants were available in the Global Migrant Origin Database. Unfortunately, we were unable to find information on the number of second-generation immigrants per community. Including a squared term to examine non-linear effects of the relative group size and a logged variant to account for the influence of extremely large and extremely small immigrant communities did not lead to different results.

The great circle distance method (Byers, 2002) was used to obtain the geographical distance between the capital cities of the country of origin and the country of destination for each separate immigrant community. The geographical distance between capital cities was measured in kilometers, and divided by 1,000 to facilitate interpretation of the effect parameters. The inclusion of a squared term to account for non-linear effects of the geographical distance between the origin country and the destination country did not lead to different findings.

\section{Individual Variables}

Gender was measured by coding men (0) and women (1). Respondents' age was measured in years; we subtracted the minimum age (15) to allow for a meaningful interpretation of the intercept. To examine the possibility of non-linear age effects on self-rated health, we also included a squared term for age. Respondents with missing information on age $(n=125)$ were assigned the mean value of age (respectively, 47.26 and 43.34 for first- and second-generation immigrants).

Immigrants' highest achieved educational level was originally measured by distinguishing seven categories. To keep the model as parsimonious as possible and to improve the comparability of the educational level measure across countries, we recoded the initial measure into three categories: not higher than lower secondary education (labeled "primary", included as the reference group), upper secondary education (labeled "upper secondary"), and higher than upper secondary education (tertiary). 
To assess respondents' employment status, we used information on their main activity in the last 7 days. To preserve parsimony, we condensed the original nine categories to four categories: "in paid employment" (reference group), "unemployed" (either actively searching for a job or not), "student", and "all other groups" (including those with missing information). We distinguished the unemployed as a separate group because unemployment is an important source of ill health as compared to other nonemployed states. We have used students as a separate category because a substantial part of our sample have not yet finished their educational career (not explicitly distinguishing this group would, therefore, be problematic for the estimation of the effect of immigrants' educational level).

To account for the fact that there may be an "urban penalty" for immigrants (Lorant, Van Oyen, and Thomas, 2008), we controlled for the level of urbanization in the area where respondents live. Five answering categories were available, all of which were included as dummy variables: a "farm or home in the countryside", a "country village", a "town or small city" (reference group), the "suburbs or outskirts of a big city", and a "big city".

To measure respondents' perceived discrimination, people were asked whether they would describe themselves as being a member of a group that is discriminated against in their country of residence (with answering categories being "yes" and "no"). In case that they replied affirmatively, they were asked on what grounds their group was discriminated against. Nine different grounds for discrimination were distinguished. Because we are specifically interested in perceived discrimination that is related to respondents' immigrant status, we focused on five grounds for discrimination: color or race, nationality, religion, language, and ethnic group. Respondents who stated that they belong to a group that is discriminated against on at least one of these grounds were coded (1) on this variable, whereas all others were coded (0).

Nine categories were originally distinguished to measure individual religious affiliation. Because we are predominantly interested in examining whether individual adherence to Islam may account for the effect of originating from a predominantly Islamic country, we condensed this measure to four categories, all of which are included as dummy variables: "Christian" (reference group), "Muslim", "other religions" (including respondents with missing information), and "none".

Immigrants' marital status is measured by distinguishing four dummy variables: "married or cohabiting" (reference group), "divorced 
or separated", "widowed", and "never married". Although cohabiting people have often been included in the never married group, we have decided to add them to the category of married people, as unmarried cohabitation has become a widespread and prominent mode of partnership in many European countries. Divorced and separated people were merged into one category since the percentage of separated people in the ESS data is small.

To measure whether respondents live with children, we distinguished two groups, both of which were included as dummy variables: "children at home" and "no children at home" (reference group).

The measurement of immigrants' social engagement was identical to the variable that was used to compute the mean level of social engagement among natives. Values range from 0 (never meeting socially with friends, colleagues, and relatives) to 6 (daily social engagement), and respondents with missing information on social engagement $(n=56)$ were assigned the mean value (i.e., 3.88 and 4.02 for first- and second-generation immigrants, respectively).

Finally, for first-generation immigrants only, information on length of stay in the destination country was obtained by asking respondents how long ago they first came to live in this country. Originally, five categories were distinguished: "within the last year", " $1-5$ years ago", "6-10 years ago", "11-20 years ago", and "more than 20 years ago". The first two categories were merged because of the low proportion of respondents that arrived within the last year.

\section{Sample Characteristics}

In Table 1, we present descriptive statistics on the origin, destination, and community variables, as well as the individual variables. This is done separately for first- and second-generation immigrants. As Table 1 demonstrates that the composition of both groups shows strong similarities, but a couple of differences are worth mentioning. The first-generation immigrants in our sample originate from countries with substantially higher levels of political suppression than the second-generation immigrants (5.99 and 5.10 respectively). Additionally, first-generation immigrants were more often born in predominantly Islamic countries than the parents of second-generation immigrants (19\% versus 11\%). Relative immigrant group size is on average larger for the second generation, whereas firstgeneration immigrants have travelled greater distances from their country 
TABLE 1

Descriptive Statistics on the Origin, Destination, and Community Characteristics, and Individual Variables; for First- and Second-Generation Immigrants Separately

\begin{tabular}{|c|c|c|c|c|c|c|}
\hline & \multicolumn{3}{|c|}{ First generation } & \multicolumn{3}{|c|}{ Second generation } \\
\hline & Range & Mean & SD & Range & Mean & SD \\
\hline \multicolumn{7}{|l|}{ Dependent variable } \\
\hline Poor self-rated health & $0 / 1$ & 0.38 & & $0 / 1$ & 0.37 & \\
\hline \multicolumn{7}{|l|}{ Origin variables } \\
\hline Adult mortality $(/ 100)$ & $0.84-4.76$ & 1.72 & 0.68 & $0.84-4.74$ & 1.61 & 0.57 \\
\hline Predominantly Islamic & $0 / 1$ & 0.19 & & $0 / 1$ & 0.11 & \\
\hline Political suppression & $2-14$ & 5.99 & 3.39 & $2-14$ & 5.10 & 2.91 \\
\hline \multicolumn{7}{|l|}{ Destination variables } \\
\hline Mean native self-rated health & $2.01-3.27$ & 2.81 & 0.31 & $2.01-3.20$ & 2.72 & 0.32 \\
\hline Mean anti-immigrant attitudes & $3.59-6.59$ & 5.07 & 0.73 & $3.96-6.59$ & 5.14 & 0.66 \\
\hline Mean native social engagement & $2.76-4.70$ & 4.00 & 0.41 & $2.76-4.70$ & 3.92 & 0.39 \\
\hline ESS survey wave $\mathrm{a}^{\mathrm{a}}$ & $0-3$ & 1.39 & 1.08 & $0-2$ & 0.86 & 0.79 \\
\hline \multicolumn{7}{|l|}{ Community variables } \\
\hline Colonial or shared past & $0 / 1$ & 0.35 & & $0 / 1$ & 0.40 & \\
\hline $\begin{array}{l}\text { Relative group size } \\
\text { (\% of total population) }\end{array}$ & $0.00-15.80$ & 2.56 & 3.97 & $0.00-15.80$ & 3.16 & 4.60 \\
\hline $\begin{array}{l}\text { Geographical distance } \\
\text { (in } 1000 \mathrm{~km} \text { ) }\end{array}$ & $0.06-18.80$ & 2.16 & 2.70 & $0.06-16.97$ & 1.25 & 1.86 \\
\hline \multicolumn{7}{|l|}{ Individual variables } \\
\hline Gender $(1$ = female $)$ & $0 / 1$ & 0.54 & & $0 / 1$ & 0.55 & \\
\hline Age $(15=0)$ & $0-82$ & 32.26 & 17.23 & $0-83$ & 28.43 & 17.64 \\
\hline \multicolumn{7}{|l|}{ Educational level } \\
\hline Primary & $0 / 1$ & 0.34 & & $0 / 1$ & 0.29 & \\
\hline Secondary & $0 / 1$ & 0.29 & & $0 / 1$ & 0.35 & \\
\hline Tertiary & $0 / 1$ & 0.33 & & $0 / 1$ & 0.34 & \\
\hline Missing & $0 / 1$ & 0.03 & & $0 / 1$ & 0.02 & \\
\hline \multicolumn{7}{|l|}{ Employment status } \\
\hline In paid employment & $0 / 1$ & 0.51 & & $0 / 1$ & 0.53 & \\
\hline Student & $0 / 1$ & 0.06 & & $0 / 1$ & 0.11 & \\
\hline Unemployed & $0 / 1$ & 0.06 & & $0 / 1$ & 0.06 & \\
\hline Other & $0 / 1$ & 0.37 & & $0 / 1$ & 0.30 & \\
\hline \multicolumn{7}{|l|}{ Urbanization } \\
\hline Farm or house in the countryside & $0 / 1$ & 0.03 & & $0 / 1$ & 0.03 & \\
\hline Country village & $0 / 1$ & 0.22 & & $0 / 1$ & 0.25 & \\
\hline Town or small city & $0 / 1$ & 0.32 & & $0 / 1$ & 0.33 & \\
\hline Suburbs or outskirts of a big city & $0 / 1$ & 0.14 & & $0 / 1$ & 0.12 & \\
\hline Big city & $0 / 1$ & 0.28 & & $0 / 1$ & 0.26 & \\
\hline Perceived discrimination ( $1=$ yes $)$ & $0 / 1$ & 0.12 & & $0 / 1$ & 0.07 & \\
\hline \multicolumn{7}{|l|}{ Religious affiliation } \\
\hline Christian & $0 / 1$ & 0.48 & & $0 / 1$ & 0.46 & \\
\hline Muslim & $0 / 1$ & 0.08 & & $0 / 1$ & 0.04 & \\
\hline Other religion & $0 / 1$ & 0.09 & & $0 / 1$ & 0.04 & \\
\hline None & $0 / 1$ & 0.34 & & $0 / 1$ & 0.46 & \\
\hline \multicolumn{7}{|l|}{ Marital status } \\
\hline Married/cohabiting & $0 / 1$ & 0.62 & & $0 / 1$ & 0.55 & \\
\hline Divorced/separated & $0 / 1$ & 0.09 & & $0 / 1$ & 0.09 & \\
\hline Widowed & $0 / 1$ & 0.09 & & $0 / 1$ & 0.07 & \\
\hline Never married & $0 / 1$ & 0.16 & & $0 / 1$ & 0.27 & \\
\hline Missing & $0 / 1$ & 0.03 & & $0 / 1$ & 0.04 & \\
\hline
\end{tabular}


TABLE 1 (Continued)

Descriptive Statistics on the Origin, Destination, and Community Characteristics, and Individual Variables; for First- and Second-Generation Immigrants Separately

\begin{tabular}{|c|c|c|c|c|c|c|}
\hline & \multicolumn{3}{|c|}{ First generation } & \multicolumn{3}{|c|}{ Second generation } \\
\hline & Range & Mean & SD & Range & Mean & SD \\
\hline \multicolumn{7}{|l|}{ Children } \\
\hline Children at home & $0 / 1$ & 0.55 & & $0 / 1$ & 0.60 & \\
\hline No children at home & $0 / 1$ & 0.44 & & $0 / 1$ & 0.39 & \\
\hline Missing & $0 / 1$ & 0.01 & & $0 / 1$ & 0.01 & \\
\hline Social engagement & $0-6$ & 3.88 & 1.56 & $0-6$ & 4.02 & 1.58 \\
\hline \multicolumn{7}{|l|}{ Length of stay } \\
\hline $0-5$ years & $0 / 1$ & 0.13 & & & NA & \\
\hline $6-10$ years & $0 / 1$ & 0.11 & & & NA & \\
\hline $11-20$ years & $0 / 1$ & 0.20 & & & NA & \\
\hline More than 20 years & $0 / 1$ & 0.55 & & & NA & \\
\hline Missing & $0 / 1$ & 0.01 & & & NA & \\
\hline
\end{tabular}

Notes: $\mathrm{NA}=$ not applicable.

${ }^{a}$ For first-generation migrants, Wave $1=0$; for second-generation migrants, Wave $2=0$.

of origin to their destination countries than the parents of the second-generation immigrants. Looking at the individual characteristics, first-generation immigrants are only slightly older than second-generation immigrants. First-generation immigrants have lower educational degrees, perceive stronger discrimination and are more often religious and in a relationship than second-generation immigrants. Although a formal comparison of first- and second-generation immigrants is not the aim of this study, these differences between both groups should at least be kept in mind when interpreting the results of the analyses. One final observation that is worth noting is that for both generations, the percentage of immigrants that reports to be Muslim ( $8 \%$ and $4 \%$, respectively) is substantially lower than the total percentage of immigrants originating from predominantly Islamic countries (19\% and $11 \%$, respectively). Because the overlap between individual affiliation to Islam and being socialized in a predominantly Islamic context appears to be rather limited, it is possible to analytically separate the effects of both variables.

\section{Analytic Strategy}

To separate origin, destination, and community effects on the one hand and effects of individual variables on the other hand, multilevel regression techniques are required. The use of non-hierarchical techniques would disregard the fact that individuals are clustered into countries of origin, countries of destination, and immigrant communities. This would lead to an 
underestimation of standard errors of origin, destination, and community effects (Snijders and Bosker, 1999; Raudenbush and Bryk, 2002). More specifically, the fact that origin countries, destination countries, and communities are not hierarchically nested in each other necessitates the use of crossclassified multilevel regression analyses. This technique is able to account for the non-nested structure of the data and to deal with the clustering of individuals into three different higher level classifications at the same time. Markov Chain Monte Carlo (MCMC) estimation techniques in MLwiN were used to estimate our models (Browne, 2003). For more technical details on cross-classified multilevel models, we refer to Raudenbush and Bryk (2002). Examples of empirical applications of these models can be found in Van Tubergen (2006) and Levels, Dronkers, and Kraaykamp (2008).

Our analytic approach consists of several steps, all of which were executed separately for first- and second-generation immigrants. First, empty models (e.g., only containing variance components) were estimated to assess to what extent variance in poor self-rated health is located at the origin country, destination country, immigrant community, and individual levels. Second, we added origin, destination, and community characteristics to the equation, which allows us to examine to what extent these characteristics influence poor self-rated health when other origin, destination, and community variables are controlled for. Third, we added the individual variables to examine to what extent the effects of the origin, destination, and community characteristics on poor self-rated health can be explained by individual attributes of immigrants. Because presenting separate models in which the individual variables are added one by one would consume too much space, we only present models in which all individual variables (both confounders and mediators) were included simultaneously. In additional models, which will only be reported textually, we examined which specific individual variables were responsible for changes in the origin, destination, and community effects. This approach allows us to more closely examine the mechanisms underlying these effects.

\section{RESULTS}

\section{Variance Components}

Table 2 sheds light on the relative contribution of the country of origin, the country of destination, and the community in influencing immigrants' health. First, empty models not containing any explanatory variables were 
TABLE 2

Variance Components of Immigrants' Poor Self-Rated Health, for First- and Second-Generation Immigrants Separately

\begin{tabular}{|c|c|c|c|c|c|c|}
\hline & \multicolumn{6}{|c|}{ Poor self-rated health } \\
\hline & \multicolumn{4}{|c|}{$\begin{array}{l}\text { Destination, origin, } \\
\text { and community } \\
\text { variables }\end{array}$} & \multicolumn{2}{|c|}{ All variables } \\
\hline \multicolumn{7}{|l|}{ First generation } \\
\hline Origin & 0.072 & $(0.028)$ & 0.065 & $(0.025)$ & 0.048 & $(0.024)$ \\
\hline Destination & 0.875 & $(0.279)$ & 0.279 & $(0.098)$ & 0.165 & $(0.063)$ \\
\hline Community & 0.095 & $(0.028)$ & 0.070 & $(0.027)$ & 0.060 & $(0.021)$ \\
\hline Individual & 3.290 & & 3.290 & & 3.290 & \\
\hline \multicolumn{7}{|c|}{ Second generation } \\
\hline Origin & 0.014 & $(0.012)$ & 0.012 & 0.013 & 0.027 & $(0.016)$ \\
\hline Destination & 0.725 & $(0.263)$ & 0.025 & 0.021 & 0.021 & $(0.017)$ \\
\hline Community & 0.027 & $(0.030)$ & 0.033 & 0.017 & 0.008 & $(0.006)$ \\
\hline Individual & 3.290 & & 3.290 & & 3.290 & \\
\hline
\end{tabular}

Notes: Standard errors in parentheses. For first-generation immigrants, $N_{\mathrm{D}}=31 ; \quad N_{\mathrm{O}}=122 ; \quad N_{\mathrm{C}}=465$; $N_{\mathrm{I}}=12,033$. For second-generation immigrants, $N_{\mathrm{D}}=28 ; N_{\mathrm{O}}=75 ; N_{\mathrm{C}}=235 ; N_{\mathrm{I}}=7177$.

estimated. For first-generation immigrants, variance in poor self-rated health is mostly located at the individual level $((3.290 /(3.290+$ $\left.0.095+0.875+0.072))^{*} 100=75.9 \%\right)$. However, in total, still $24.1 \%$ of variance is located at any of the higher levels, which underlines that immigrants' health is strongly dependent on factors beyond characteristics of the individual. In comparison to the origin (1.7\%) and community $(2.2 \%)$ levels, destination countries account for the largest part of variation in immigrants' health $(20.2 \%)$. This suggests that immigrants' current living environment, and especially the receiving society as a whole, is far more important than living conditions prior to migration in determining health. For second-generation immigrants, a similar picture appears, although individual characteristics have a stronger relative contribution to variation in immigrants' self-rated health (81.1\%). Again, variation is by far more strongly located at the destination level (17.9\%) than at the origin $(0.3 \%)$ and community $(0.7 \%)$ levels. These findings suggest that the country of origin of second-generation immigrants' parents barely has a lasting influence on their offspring's health.

Second, we examined the reduction in variation in immigrants' selfrated health after including all origin country, destination country, and community characteristics. The results are presented in the second column of Table 2. For first-generation immigrants, especially the substantial reduction in variance at the destination level is worth mentioning (from 0.875 to 0.279 ). Apparently, the destination characteristics in our model 
are to a large extent responsible for variation in immigrants' health across destination countries. Community variance is reduced substantially as well (from 0.095 to 0.070 ) by accounting for the community characteristics in our model. Origin variance in poor self-rated health barely changes after accounting for origin characteristics. For the second generation, the pattern is similar, yet more dramatic: variance in immigrants' self-rated health between destination countries is nearly nullified after accounting for the destination characteristics in our model. Adding all individual characteristics as a third step resulted in a further substantial reduction in most variance components for both generations. In sum, for both firstand second-generation immigrants, the variables used in our models are to a very large extent able to explain why immigrants' health varies across origin countries, destination countries, and immigrant communities.

\section{Cross-Classified Multilevel Models}

As a next step, cross-classified multilevel models were used to examine the effects of all variables on poor self-rated health. In Table 3, results of logistic cross-classified multilevel regressions of first- and second-generation immigrants' self-rated health are presented. In Model 1 and Model 3, only effects of origin, destination, and community characteristics were estimated. In Model 2 and Model 4, individual variables were added to the equation. Hypothesis 1 is not supported by the results: adult mortality rates in the country of origin are not associated with immigrants' self-rated health. For first-generation immigrants, Hypothesis 2 finds support in our findings: as expected, immigrants from predominantly Islamic countries of origin report better health than respondents from countries with other predominant denominations. This association persists after controlling for individual adherence to Islam in Models 2 and 4. The odds of reporting poor health is $24.4 \%\left(1-e^{-0.280}\right)$ lower among immigrants from predominantly Islamic countries, which is quite a substantial difference. Originating from predominantly Islamic countries does not appear to be associated with reporting better health for second-generation immigrants.

In concordance with Hypothesis 3, a higher level of political suppression in the origin country is related to poorer self-rated health for both generations. For second-generation immigrants, this is only the case after accounting for individual characteristics. Additional analyses have shown that the relationship between political suppression in the origin country and self-rated health was suppressed by immigrants' age and 


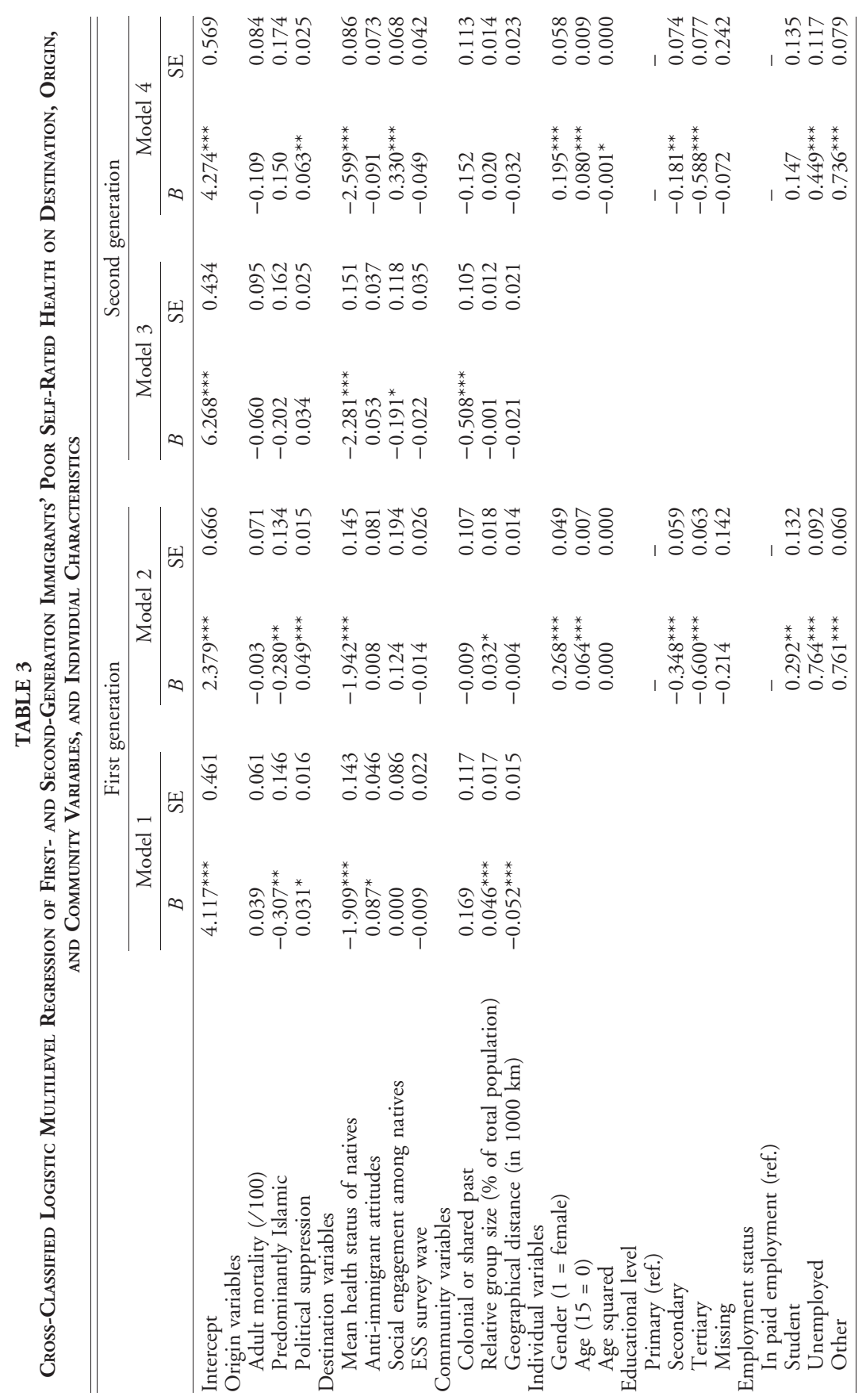




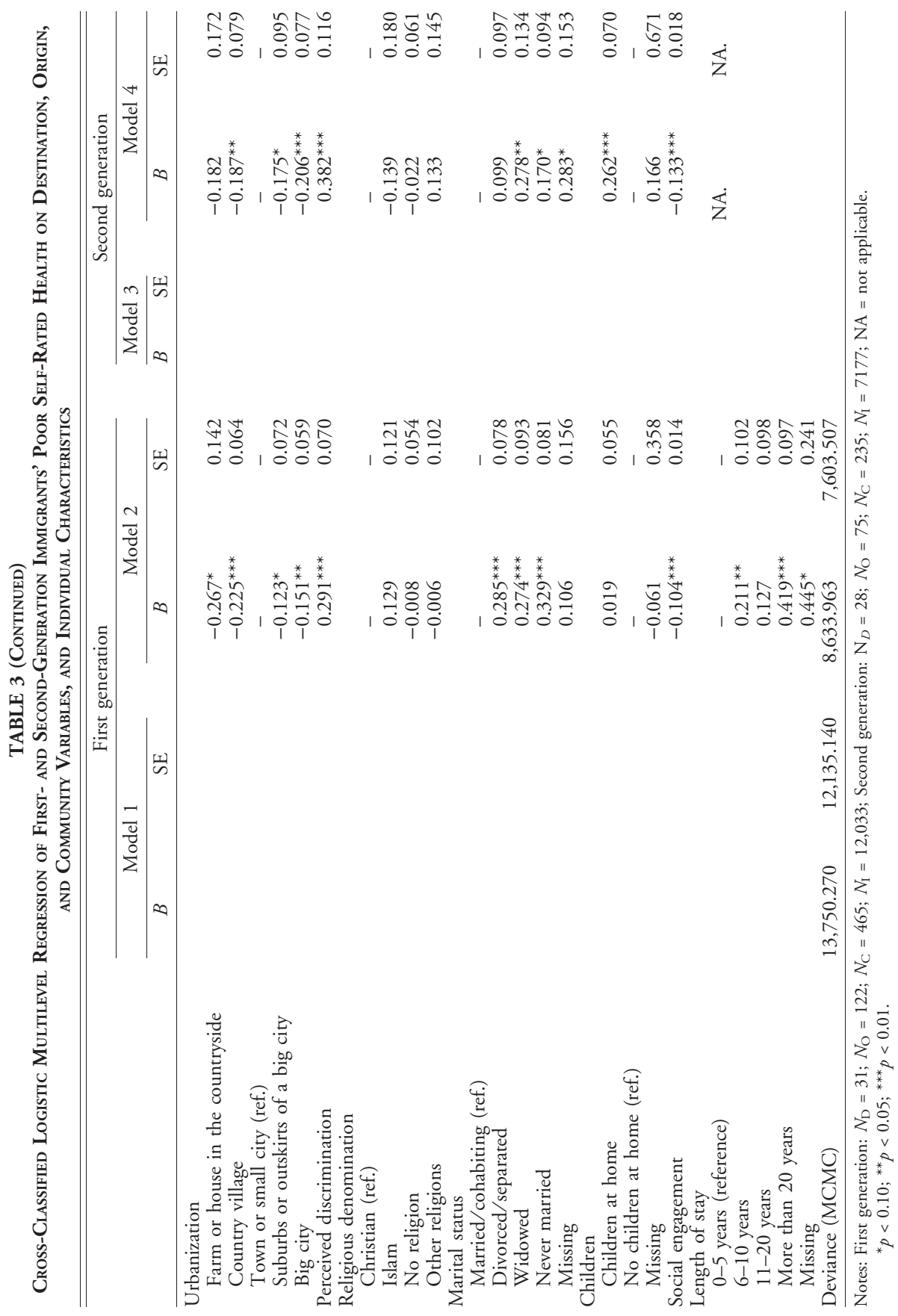


educational level. Accounting for this suppression effect, a point increase in the political suppression scale is associated with a $5.0 \%$ (i.e., $e^{0.049}$ ) increase of the odds to report poor health. In sum, Hypothesis 1 appears to be supported for both first- and second-generation immigrants.

Looking at the results for the destination effects, Hypothesis 4 is clearly supported for both first- and second-generation immigrants: Immigrants' health is strongly related to the mean health status of natives in the country of destination. It appears that immigrants' health is very strongly influenced by factors that also determine the health of native inhabitants of their country of destination. Hypothesis 5 is only supported for first-generation immigrants: as we expected, living in countries in which attitudes toward immigrants are more strongly disapproving is associated with poor self-rated health. Controlling for individual characteristics in Model 4, this origin effect is no longer significant. Additional analyses revealed that this was mostly due to the inclusion of individual perceived discrimination.

Finally, for first-generation immigrants, social engagement among natives is not related to poor health among immigrants. For second-generation immigrants, a high level of social engagement among natives in the destination country appears to be associated with better self-rated health in Model 3. However, taking individual characteristics into account leads to the conclusion that immigrants are actually worse off in countries with high levels of social engagement among natives. Additional analyses demonstrated that this radical switch of signs is because of two factors. First, controlling for age renders the effect of natives' social engagement nonsignificant. The finding of better health in countries with higher levels of social engagement is therefore owing to the fact that second-generation immigrants are younger in destination countries with higher levels of social engagement. Second, the negative impact of natives' social engagement on health appeared to be suppressed by individual social ties (i.e., marital status, children, and individual social engagement). Accounting for the fact that immigrants have stronger individual social networks in countries with high levels of social engagement among natives, high social engagement among natives appears to be detrimental to immigrants' health. Hence, support is found for Hypothesis 6b, whereas Hypothesis 6a is not supported. Immigrants' self-rated health does not vary significantly between survey waves.

In Hypothesis 7, we expected a beneficial influence of living in countries that have colonial or shared historical ties with the country of origin on immigrants' health. In communities of this kind, second-generation 
immigrants have $39.8 \%\left(1-e^{-0.508}\right)$ lower odds of reporting poor health. However, the association is strongly reduced after taking individual characteristics into account in Model 4. Additional analyses revealed that the effect of colonial or shared historical ties on health is mainly explained by differences in the age composition between communities (i.e., on average, immigrants from communities with colonial ties between the country of origin and the country of destination are younger than other second-generation immigrants). Hence, the found association between a colonial or shared past and self-rated health appears to be spurious. For first-generation immigrants, Model 1 indicates that a colonial or shared history between the country of origin and the country of destination is not significantly related to self-rated health. All in all, Hypothesis 7 is not supported by our results.

For first-generation immigrants, the relative group size of immigrants' communities is negatively associated with health: Regardless of whether individual characteristics are accounted for, immigrants report poorer health as their specific immigrant community is larger relative to the total population of the destination country. With every percent point increase in the relative group size, the odds of reporting poor health are $3.3 \%$ higher $\left(e^{0.032}\right)$. This means that Hypothesis $8 \mathrm{~b}$, in which we hypothesized that immigrants would report poorer health as the relative size of their immigrant community is larger, finds support with our findings, whereas Hypothesis $8 \mathrm{a}$, in which the opposite was expected, is not supported. In contrast to first-generation immigrants, second immigration immigrants do not experience either harmful or beneficial consequences to their health from living among large numbers of peers.

Finally, we find support for Hypothesis 9, because first-generation immigrants indeed appear to report better health as the geographical distance between the country of origin and the country of destination is larger. After controlling for individual characteristics, this association is strongly reduced. Additional analyses have shown that this is because of controlling for immigrants' length of stay in the destination countries: Because the healthy migrant advantage rapidly vanishes after arrival in the destination country, this health selection effect is explained when controlling for length of stay. As we expected, Hypothesis 9 is not supported for second-generation immigrants, because obviously health selection mechanisms did not operate for the offspring of immigrants.

The effects of the individual variables on immigrants' health in Model 2 and Model 4 are largely in concordance with results from earlier 
studies on both immigrants and the general population, and will, therefore, not be discussed in great detail. Instead, we limit ourselves to highlighting a small number of interesting findings. First, we find no evidence for an "urban health penalty": immigrants living in towns or small cities report the poorest health, rather than immigrants in the most urbanized areas. Second, perceived discrimination is related to reporting poorer health: In fact, first-generation immigrants who perceived to be discriminated against had $33.8 \%\left(e^{0.291}\right)$ higher odds of poor health. This detrimental impact of perceived discrimination on immigrants' health remains present in the second generation. This parallels findings from earlier work, and suggests that immigrants encounter prejudice and hostility even if they were born in the country they live in (Smith, Kelly, and Nazroo, 2009). Third, whereas originating from predominantly Islamic countries appeared to have a salutary effect, individual adherence to Islam is not associated with better health. Fourth, individual social engagement appears to be beneficial to immigrants' health, which seems counterintuitive given the detrimental impact of high levels of social engagement among natives and large immigrant community size. Finally, second-generation immigrants with children living at home have $30.0 \%\left(e^{0.262}\right)$ higher odds of reporting poor health. Possibly, for second-generation immigrants, raising children may be associated with conflicts between their own upbringing (first-generation immigrants may raise their children based on common practice in the country of origin) and the dominant culture of the destination country.

\section{CONCLUSIONS AND DISCUSSION}

In this study, we examined the influence of characteristics of the country of origin, the country of destination, and communities on first- and second-generation immigrants' self-rated health in Europe. Using a double comparative design in which cross-classified multilevel techniques were employed, this study is innovative in theoretically and analytically disentangling origin, destination, and community effects. First, we have demonstrated that characteristics of the country of origin have a lasting influence on immigrants' health. High levels of political suppression in the country of origin are related to poorer health, both among first- and second-generation immigrants. This may either indicate that traumatic experiences prior to migration of first-generation immigrants induce stress among immigrants' offspring, or that the presence of relatives in 
politically suppressive regimes is harmful to immigrants' health, even if they have been brought to safety themselves. Additionally, even after accounting for individual adherence to Islam, first-generation immigrants originating from predominantly Islamic countries report better health than immigrants from societies with other predominant religious denominations. This implies that socialization of healthy behavior and the sanctioning of unhealthy habits in early life continue to determine immigrants' lifestyle patterns after migration. For second-generation immigrants, we did not find a relationship, indicating that parents from predominantly Islamic societies do not pass their healthy lifestyle on to their offspring. Of course, doing so would be difficult in countries of destination with other dominant religious groups. The health of natives in the country of origin does not have a lasting influence on immigrants' health. The suggestion made in earlier work that illness and deprivation in early life may account for variations in immigrants' health is, therefore, not supported in this study. Although our study suggests that the role of living conditions prior to migration is limited, future research should consider additional indicators of conditions in early life to offer a more comprehensive evaluation of the role of circumstances in the country of origin.

Second, characteristics of the destination country prove to be particularly important in explaining immigrants' health. Most importantly, immigrants' health is strongly associated with the health of natives in the destination country. This implies that immigrants adapt to the lifestyles (e.g., dietary habits, smoking, alcohol consumption, and physical exercise) of the other inhabitants of their country of destination. Additionally, this may suggest that the quality of the health care system in the country of destination is important for determining the risk of ill health for both immigrants and natives. All else being equal, a high level of social engagement among natives in the country of destination appeared to be detrimental for second-generation immigrants' health. Instead of lessening acculturation problems and promoting social interaction, strong social networks among natives may in fact hamper social integration of immigrants' into the destination country. Possibly, social capital is divided along ethnic lines, and strong bonding social capital (i.e., ties within the own ethnic group) may hamper the formation of bridging social ties between immigrants' offspring and natives. Because we were only able to examine informal social engagement, future research should examine whether using measures of formal social participation, such as involvement in voluntary associations, would lead to 
different results. Anti-immigrant attitudes among natives in the destination country only have an impact on first-generation immigrants' health. Although perceived discrimination is indeed a strong predictor of ill health, it is not entirely clear from our results to what extent indicators of discrimination at the macro level actually induce perceived discrimination. Interestingly, perceived discrimination appears to be especially harmful for second-generation immigrants. For them, being born and bred in a society by which they feel regarded as unwanted strangers may be especially stressful. For now, we conclude that theoretical perspectives on the role of discrimination find support in this study, but we urge future research to further investigate the underlying causes of immigrants' perceptions of discrimination.

Third, independently of characteristics of the country of origin and the country of destination, characteristics of specific immigrant communities appeared to contribute to immigrants' risk of reporting ill health. Instead of having beneficial consequences to immigrants' health, belonging to immigrant groups that comprise a relatively large proportion of the population is associated with reporting poorer health. This study, therefore, contradicts ethnic social capital theory and findings from earlier work which suggested that the presence of large numbers of immigrant peers from the same country of origin in the country of destination offers social support, companionship, and better opportunities of obtaining employment. Our findings rather support the argument that living in large immigrant communities hampers the social integration and acculturation of immigrants into society as a whole. However, for second-generation immigrants, no association was found. This may reflect the fact that for the second generation social ties within the own immigrant group are more strongly paralleled by social integration into other segments of the destination country. The finding that a larger geographical distance between the country of origin and the country of destination is associated with better health among first-generation immigrants indicates the presence of health selection effects. The fact that this relationship is explained by accounting for immigrants' length of stay further supports this argument. Contrary to acculturation theory, cultural proximity, as measured by the presence of colonial or shared historical ties between the country of origin and the country of destination, is not related to immigrants' health. All else being equal, the benefits of acquaintance with the culture of the destination country suggested in earlier work do not come to the fore in our findings. 
There are certain limitations to this study, some of which may be dealt with in future research. First, the cross-cultural validity of the selfrated health scale has been questioned (Uniken Venema, Garretsen, and Van der Maas, 1995). However, the available evidence suggests that our self-rated health measure is actually quite comparable across ethnic groups (McGee et al., 1999; Chandola and Jenkinson, 2000). Second, to identify first- and second-generation immigrants, we have relied on information on country of birth. Because this measure has both advantages and disadvantages as compared to other indicators (e.g., ethnic group), future research should complement information on country of birth with other information when classifying immigrants (Stronks, Kulu-Glasgow, and Agyemang, 2008). Unfortunately, no other indicators were available in our data to take a first step in this direction. Third, although our findings certainly suggest that health selection may partly account for variation in immigrants' health, conclusions on selectivity based on cross-sectional data remain tentative (Kasl and Berkman, 1983). Ideally, future research should, therefore, include measurements of immigrants' health prior to migration as well as at several time points after migration. Finally, although self-rated health is a strong predictor of morbidity and mortality, the origin, destination, and community characteristics in our study may differently influence different health indicators. To further elucidate the mechanisms underlying the relationship between immigration and health, we urge scholars to examine specific indicators of morbidity and wellbeing in future research (Uniken Venema, Garretsen, and Van der Maas, 1995.

To conclude, the main message of this study seems that immigrants' health shows strong resemblance to the health of native inhabitants of their country of destination. In light of the general debate in medical sociology and social epidemiology on the relative contribution of early life conditions and the current living environment in shaping health, our study suggests that the role of the latter is by far more important than the former. From a policy perspective, this implies that people's health can be strongly influenced in all stages of life, and that interventions to promote health should certainly not be limited to early life. On the other hand, the fact that characteristics of the country of origin such as political suppression and religious denominations continue to influence health after emigration suggest that some determinants of health have a lasting impact and are difficult to change even with a radical change of living environment. In general then, conditions in early life and the current living 
environment appear to complement each other in determining people's health. Additionally, the fact that we still find variation in health among second-generation immigrants implies that being born in a country is not sufficient to be equally healthy as people whose families have been living in this country for generations. Most notably, the strong effect of perceived discrimination on second-generation immigrants' risk of ill health calls for attention. Our study suggests that reducing perceptions of discrimination among this group may lead to a substantial reduction of health problems of immigrants in European societies.

\section{APPENDIX}

Procedure for Distinguishing First-Generation Immigrants and Second-Generation Immigrants in the European Social

Surveys (2002-2008)

Two questions in the data were used to assign respondents to the first generation, second generation, and native categories. First, respondents were asked whether they were born in the country in which the interview took place. If they answered that this was not the case, they were classified as first-generation immigrants. We decided to consider people who were born abroad as first-generation migrants, regardless of the country of birth of their parents. It could be argued that respondents whose parents were both not born abroad (e.g., children of expatriates and re-migrants, and people who were adopted as a child) should not be regarded as immigrants. However, even though their parents were born and socialized in the country of destination, living conditions in the country of origin in early life may have had a lasting influence on these respondents. Additionally, for this group, the migration experience may still have had a stressful impact. Including a dummy variable for this group (11.1\% of first-generation immigrants) in the analyses did not change the results. Moreover, the parameter of the dummy was not significant, indicating that there is indeed no difference in self-rated health between this group and other first-generation immigrants. For these reasons, we did not exclude this specific group from the sample of first-generation immigrants.

Second, regardless of their own country of birth, respondents were asked whether their mother and father were born in the country in which the survey was conducted. If the respondent and both parents were born 
in the country in which the interview took place, the respondent was categorized as a native inhabitant of this country. In case that the respondent was born in the country of residence, but at least one of both parents was not, the respondent was classified as a second-generation migrant. Earlier research has suggested that having one native parent may have both beneficial and detrimental consequences for second-generation immigrants' health, as compared to people with two immigrant parents (Saraiva Leao et al., 2005, 2009; Safi, 2010). In concordance with estimates by Safi (2010), a large percentage of second-generation immigrants $(69.7 \%)$ in the ESS data appeared to have one native parent. In our analyses, adding a dummy variable distinguishing second-generation immigrants with one native parent did not lead to different results. Additionally, the effect of the dummy itself was not significant, meaning that there is no difference in self-rated health between both groups of second-generation immigrants. Therefore, in the remainder of this study, no distinction into different second-generation immigrant groups was made. As a result, we were able to identify 14,559 first-generation immigrants (8.5\%), 12,240 second-generation immigrants (7.1\%), and 142,395 natives $(83.6 \%)$. We were unable to classify 1,206 respondents $(0.7 \%)$ because of missing information on either their own country of birth, or both parents' country of birth (in case that information on only one parent was available, this information was used for the categorization).

As a next step, we assigned a country of origin to all first- and second-generation immigrants. All first-generation immigrants were asked in which country they were born. For second-generation immigrants, we used information on the country of birth of both parents. If both parents were born abroad, and in the same country, this country was used as the country of birth. In case that both parents were born abroad, but in different countries, we followed Levels, Dronkers, and Kraakkamp (2008) in using the maternal country of birth. If only one parent was born abroad, we used this parent's country of birth. Again, if information on only one parent was available, this information was used for the categorization. Unfortunately, in the 2002 wave of the ESS, no country of origin could be determined for second-generation immigrants, because respondents were not asked for their parents' country of birth. As a result, the 3,398 second-generation immigrants in the 2002 wave $(27.8 \%$ of all second-generation immigrants) could not be used in our analyses. In addition, since Israel and Italy were only surveyed in the 2002 ESS wave, for these countries only first-generation immigrants could be identified. 
In total, 203 different countries of origin were assigned to respondents. Although respondents in the ESS were urged to name their (and their parents') country of origin based on the political situation at the time of the interview, some respondents still reported countries that by then had ceased to exist. We decided to exclude respondents who reported to be (the child of parents) born in Czechoslovakia, USSR, and Yugoslavia for practical reasons: we have no information on the former region (and present day country) of origin for these respondents, and we used information from 1990 and later to measure the origin characteristics in our study. (Note that respondents who reported to originate from any of the present day countries (e.g., Latvia, Russia, Slovakia, and Croatia) were still included). Germany and DDR were treated as one single country of origin; similar decisions were made for Aruba and the Netherlands Antilles and Serbia and Montenegro. These decisions left us with 197 countries of origin.

\section{REFERENCES}

Abraido-Lanza, A. F., B. P. Dohrenwend, D. S. Ng-Mak, and J. Turner

1999 "The Latino Mortality Paradox: A Test of the "Salmon Bias" and Healthy Migration Hypotheses." American Journal of Public Health 89:1543-1548.

Anson, J.

2002 "Immigrant Mortality in Belgium: The Person and the Place." Archives of Public Health 60:1-21.

Becares, L., J. Nazroo, and M. Stafford

2009 "The Buffering Effects of Ethnic Density on Experienced Racism and Health." Health \& Place 15:700-708.

Berry, J. W., U. Kim, T. Minde and D. Mok

1987 "Comparative Studies of Acculturative Stress." International Migration Review 21:491-511.

Bos, V. et al.

2004 "Ethnic Inequalities in Age- and Cause-Specific Mortality in The Netherlands." International Journal of Epidemiology 33:1112-1119.

Browne, W. J.

2003 MCMC Estimation in MLwiN. London: Centre for Multilevel Modeling.

Byers, J. A.

2002 Great Circle Distances Calculated Between Points on Earth.<http://www.chemicalecology.net/moregen>. Accessed October 3, 2009.

Carballo, M., J. J. Divino, and D. Zeric

1998 "Migration and Health in the European Union." Tropical Medicine and International Health 3:936-944. 
Castles, S., and M. J. Miller

2003 The Age of Migration: International Population Movements in the Modern World. New York, NY: Guildford Press.

Chandola, T., and C. Jenkinson

2000 "Validating Self-Rated Health in Different Ethnic Groups." Ethnicity and Health 5:151-159.

CIA

2009 The World Factbook 2009. Washington, DC: Central Intelligence Agency.

Clarke, P.

2008 "When Can Group Level Clustering Be Ignored? Multilevel Models Versus SingleLevel Models With Sparse Data." Journal of Epidemiology and Community Health 62:752-758.

Evans, J.

1987 "Introduction: Migration and Health." International Migration Review 21:v-xiv.

Finch, B. K., B. Kolody, and W. A. Vega

2000 "Perceived Discrimination and Depression Among Mexican-Origin Adults in California." Journal of Health and Social Behavior 41:295-313.

Freedom House

2009 <http://www.freedomhouse.org>. Accessed September 30, 2009.

Gagnon, A., and R. Mazan

2009 "Does Exposure to Infectious Diseases in Infancy Affect Old-Age Mortality? Evidence From a Pre-Industrial Population." Social Science \& Medicine 68:1609-1616.

Gee, G. C.

2002 "A Multilevel Analysis of the Relationship Between institutional and Individual Racial Discrimination and Health Status." American Journal of Public Health 92:615-623.

Harding, S.

2004 "Mortality of Migrants From the Caribbean to England and Wales: Effect of Duration of Residence." International Journal of Epidemiology 33:382-386.

Hjern, A., and P. Allebeck

2004 "Alcohol-Related Disorders in First- and Second-Generation Immigrants in Sweden: A National Cohort Study." Addiction 99:229-236.

Ho, L., V. Bos, and A. Kunst

2007 "Differences in Cause-of-Death Patterns Between the Native Dutch and Persons of Indonesian Descent in the Netherlands." American Journal of Public Health 97:1616-1618.

Idler, E., and Y. Benyamini

1997 "Self-Rated Health and Mortality: A Review of Twenty-Seven Community Studies." Journal of Health and Social Behavior 38:21-37.

Jowell, R., and The Central Co-ordinating Team

2003 European Social Survey 2002/2003: Technical Report. London: Centre for Comparative Social Surveys, City University.

2005 European Social Survey 2004/2005: Technical Report. London: Centre for Comparative Social Surveys, City University. 
2007 European Social Survey 2006/2007: Technical Report. London: Centre for Comparative Social Surveys, City University.

2009 European Social Survey 2008/2009: Technical Report. London: Centre for Comparative Social Surveys, City University.

Karlsen, S. et al.

2005 "Racism, Psychosis and Common Mental Disorder Among Ethnic Minority Groups in England." Psychological Medicine 35:1795-1803.

Kasl, S. V., and L. Berkman

1983 "Health Consequences of the Experience of Migration." Annual Review of Public Health 4:69-90.

Kawachi, I., B. P. Kennedy, and R. Glass

1999 "Social Capital and Self-Rated Health: A Contextual Analysis." American Journal of Public Health 89:1187-1193.

Knipscheer, J. W., and R. J. Kleber

2006 "The Relative Contribution of Posttraumatic and Acculturative Stress to Subjective Mental Health Among Bosnian Refugees." Journal of Clinical Psychology 62:339353.

Krieger, N., and S. Sidney

1996 "Racial Discrimination and Blood Pressure: The CARDIA Study of Young Black and White Adults." American Journal of Public Health 86:1370-1378.

Kuo, W.

1976 "Theories of Migration and Mental Health: An Empirical Testing on Chinese Americans." Social Science and Medicine 10:297-306.

LeClere, F. B., R. G. Rogers, and K. D. Peters

1997 "Ethnicity and Mortality in the United States: Individual and Community Correlates." Social Forces 76:169-198.

Levels, M., J. Dronkers, and G. Kraaykamp

2008 "Immigrant Children's Educational Achievement in Western Countries: Origin, Destination, and Community Effects on Mathematical Performance." American Sociological Review 73:835-853.

Lindstrom, M., and J. Sundquist

2002 "Ethnic Differences in Daily Smoking in Malmo, Sweden." European Journal of Public Health 12:287-294.

Lorant, V., H. Van Oyen, and I. Thomas

2008 "Contextual Factors and Immigrants' Health Status: Double Jeopardy." Health \& Place 14:678-692.

Major, E. F.

1996 "The Impact of the Holocaust on the Second Generation: Norwegian Jewish Holocaust Survivors and their Children." Journal of Traumatic Stress 9:441-454.

McGee, D. L., Y. Liao, G. Cao, and R. S. Cooper

1999 "Self-Reported Health Status and Mortality in a Multiethnic US Cohort." American Journal of Epidemiology 149:41-46. 
Parsons, C. R., R. Skeldon, T. L. Walmsley and L. A. Winters

2007 Quantifying International Migration: A Database of Bilateral Migrant Stocks. World Bank Research Working Paper, WPS4165

Pickett, K. E., and R. G. Wilkinson

2008 "People Like us: Ethnic Group Density Effects on Health." Ethnicity and Health 13:321-334.

Portes, A.

1998 "Social Capital: Its Origins and Applications in Modern Sociology." Annual Review of Sociology 24:1-24.

Pudaric, S., J. Sundquist, and S. E. Johansson

2003 "Country of Birth, Instrumental Activities of Daily Living, Self-Rated Health and Mortality: A Swedish Population-Based Survey of People Aged 55-74." Social Science \& Medicine 56:2493-2503.

Raudenbush, S. W., and A. S. Bryk

2002 Hierarchical Linear Models. Applications and Data Analysis Methods. Newbury Park, CA:Sage.

Razum, O., H. Zeeb, H. S. Akgun and S. Yilmaz

1998 "Low Overall Mortality of Turkish Residents in Germany Persists and Extends into a Second Generation: Merely a Healthy Migrant Effect?" Tropical Medicine and International Health 3, 297-303.

Reijneveld, S. A.

1998 "Reported Health, Lifestyles, and Use of Health Care of First Generation Immigrants in The Netherlands: Do Socioeconomic Factors Explain their Adverse Position?." Journal of Epidemiology and Community Health 52:298-304.

Safi, M.

2010 'Immigrants' Life Satisfaction in Europe: Between Assimilation and Discrimination." European Sociological Review Advance access 26:159-176.

Saraiva Leao, T. et al.

2005 "Incidence of Mental Disorders in Second-Generation Immigrants in Sweden: A Four-Year Cohort Study.” Ethnicity and Health 10:243-256.

- J. Sundquist, S. E. Johansson and K. Sundquist

2009 "The Influence of Age at Migration and Length of Residence on Self-Rated Health Among Swedish Immigrants: A Cross-Sectional Study." Ethnicity and Health 14: 93-105.

Singh, G. K., and M. Siahpush

2002 "Ethnic-Immigrant Differentials in Health Behaviors, Morbidity, and CauseSpecific Mortality in the United States: An Analysis of two National Data Bases." Human Biology 74:83-109.

Smith, N. R., Y. J. Kelly, and J. Y. Nazroo

2009 "Intergenerational Continuities of Ethnic Inequalities in General Health in England." Journal of Epidemiology and Community Health 63:253-258.

Snijders, T. A. B., and R. J. Bosker

1999 Multilevel analysis: An introduction to basic and advanced multilevel modelling. London: Sage. 
Stirbu, I. et al.

2006a "Cancer Mortality Rates Among First and Second Generation Migrants in the Netherlands: Convergence Toward the Rates of the Native Dutch Population." International Journal of Cancer 119:2665-2672.

- A. E. Kunst, V. Bos and J. P. Mackenbach

2006b "Differences in Avoidable Mortality Between Migrants and the Native Dutch in the Netherlands." BMC Public Health 6:78-88.

Stronks, K., I. Kulu-Glasgow, and C. Agyemang

2008 "The Utility of 'Country of Birth' for the Classification of Ethnic Groups in Health Research: The Dutch Experience." Ethnicity and Health 14:1-14.

Uniken Venema, H. P., H. F. L. Garretsen, and P. J. Van der Maas

1995 "Health of Migrants and Migrant Health Policy, the Netherlands as an Example." Social Science and Medicine 41:809-818.

Van Tubergen, F.

2006 Immigrant Integration: A Cross-National Study. New York, NY: LFB Scholarly Publishing.

Vega, W. A., and R. G. Rumbaut

1991 "Ethnic Minorities and Health." Annual Review of Sociology 17:351-383.

Veling, W. et al.

2007 "Discrimination and the Incidence of Psychotic Disorders Among Ethnic Minorities in The Netherlands." International Journal of Epidemiology 36:761-768.

et al.

2008 "Ethnic Density of Neighborhoods and Incidence of Psychotic Disorders among Immigrants." American Journal of Psychiatry 165:66-73.

Westman, J. et al.

2008 "Migration and Self-Rated Health: A Comparison Between Finns living in Sweden and Finns living in Finland." Scandinavian Journal of Public Health 36:698-705.

WHO

2009 World Health Organization Statistical Information System (WHOSIS).<http:// www.who.int/whosis/en/index>. Accessed October 3, 2009.

Wiking, E., S. E. Johansson, and J. Sundquist

2004 "Ethnicity, Acculturation, and Self Reported health. A Population Based Study Among Immigrants from Poland, Turkey, and Iran in Sweden." Journal of Epidemiology and Community Health 58:574-582.

Williams, D. R., H. W. Neighbors, and J. S. Jackson

2003 "Racial/Ethnic Discrimination and Health: Findings from Community Studies." American Journal of Public Health 93:200-208.

World Bank

2007 Migration and Remittances. Washington, DC: The World Bank. 